\title{
A convenient self-referencing mood induction procedure
}

\author{
PENNIE S. SEIBERT and HENRY C. ELLIS \\ University of New Mexico, Albuquerque, New Mexico
}

\begin{abstract}
We describe a brief, convenient, and effective procedure for experimentally inducing mood states in the laboratory that are especially useful in the study of cognition and emotion. The procedure is like that of Velten's (1968) in that a verbal self-instructional procedure is used to induce a temporary mood state. It differs from Velten's in that the mood induction items contain current language usage familiar to typical college undergraduates, contain no reference to potential cognitive processing deficits or strategies that may either interfere with or facilitate performance on some criterion cognitive task, contain no reference to suicidal or somatic states, and is briefer than Velten's procedure in that only 25 , rather than 60 , items are employed. Validation of the mood induction procedure demonstrated that the induction procedures were effective, as assessed by a depression adjective checklist (DACL), and that the induction of both sad and happy moods produced poorer recall than did a neutral mood control.
\end{abstract}

The study of the effects of emotional mood states on memory and other cognitive processes has flourished in recent years. Several theoretical perspectives have been developed to interpret the various effects associated with emotional mood states (Bower, 1981; Ellis \& Ashbrook, 1988). Furthermore, a broad range of methodologies and procedures have been used to study the effects of emotional mood states on cognitive task performance (Ellis \& Ashbrook, 1989). Ellis and Hunt (1989, pp. 275-295) have summarized a number of the cognition-emotion research findings that show that disruptive emotional states are frequently accompanied by poorer performance on cognitive tasks. Further examples of this research include findings that emotional states are associated with changes in social judgments (Forgas \& Bower, 1988), mood congruent effects (Blaney, 1986), and state dependent effects (Bower \& Mayer, 1989).

The procedures employed in studies of cognitionemotion relationships have included various types of mood manipulations, including hypnosis (e.g., Bower \& Mayer, 1989; Friswell \& McConkey, 1989), giving gifts or success/ failure manipulation (e.g., Isen, 1984), music mood induction (e.g., Kenealy, 1988), imaging (e.g., Gage \& Safer, 1985), mood posturing (e.g., Sirota \& Schwartz, 1982), recalling emotional memories (e.g., Brewer, Doughtie, \& Lubin, 1980), and the most widely used technique, a self-referencing mood induction procedure developed by Velten (1968).

We would like to thank Beverly Herbert, Greg Seibert, Regina Prizont, Larry Varner, Marylou Christophersen, Deneen Crandell, Ellen Pick, and Casey Caldwell for their assistance in developing the mood induction scales. Requests for reprints can be sent to Pennie S. Seibert, who is now at the Department of Psychology, Boise State University, Boise, ID 83725, or Henry C. Ellis, Department of Psychology, University of New Mexico, Albuquerque, NM 87131.
Similarly, a wide range of measures used to assess mood states has been developed. There is general agreement that some type of mood assessment of experimentally induced mood states is necessary in laboratory studies of cognition and emotion. The most commonly employed measures of mood states are the Depression Adjective Checklist (DACL; Lubin, 1965), Beck's (1978) Depression Inventory, the Multiple Affect Adjective Checklist (Zuckerman, Lubin, Vogel, \& Valerius, 1964), and the Profile of Mood States (McNair, Lorr, \& Droppleman, 1971).

Mood induction procedures can be useful in laboratory investigations of the cognition-emotion relationships, particularly when the procedures have been constructed in accordance with certain criteria. Many researchers have argued that the more self-referencing and/or selfevaluating a mood induction system is, the more likely an intense and meaningful emotional mood state will be produced (Hoh, McLennan, \& Ho, 1987; Mayer \& Salovey, 1988; Pietromonaco \& Markus, 1985; Rholes, Riskind, \& Lane, 1987; Scheier \& Carver, 1977). If the mood induction procedure enables self-referencing, subjects are likely to become more directly or personally involved and thus experience an emotional state conceivably more akin to naturally occurring mood states. Additionally, it may be that increased personal involvement stimulates greater intensity of the mood effect (Blaney, 1986; Ucros, 1989). Sufficiently intense moods are necessary to maximize the effects of the mood induction on cognitive processes (Ellis \& Ashbrook, 1989) and to be reflected in manipulation checks (Kenealy, 1986).

Another consideration is that the mood induction procedure is most useful for laboratory research if it is transient in nature, but that the emotional state remains a sufficient amount of time necessary for the purposes of a 
particular cognition-emotion investigation (Sherwood, Schroeder, Abrami, \& Alden, 1985).

This paper introduces a convenient approach to transient mood induction using self-referencing statements in conjunction with a free-association technique. Inventories for the induction of happy, sad, and neutral (control) groups are provided.

\section{Construction of the Mood Induction Scales}

Two researchers who were experienced in mood induction procedures drafted three lists of self-referent statements: one list was devoted to sentences designed to induce a happy mood, one for sad, and one for neutral sentences. The statements were drafted according to the following four criteria: (1) all statements must enable selfreferencing, (2) no reference to somatic states, (3) no reference to suicide, and (4) no reference to cognitive processing. A panel of eight research assistants then selected 25 statements from each mood category and ordered the statements according to judged intensity.

The mood induction scales and instructions were refined in an ongoing process according to information contributed by eight experimenters who monitored the mood induction procedures as experienced by 144 undergraduate male and female student volunteers. The experimenters noted any potential problems that were associated with particular statements; the statements found to be possibly problematic were amended. For example, while observing subjects free-associating to various series of mood induction statements, we noticed that they responded poorly to statements that were composed of language that they did not normally use. When that happened, subjects exhibited mood inappropriate behaviors, such as laughing during sad mood induction or saying, "That's stupid." Such mood inappropriate behaviors can readily inhibit the mood induction process. Therefore, if the students had difficulty relating to or understanding a particular statement because of language use, the sentence was modified to reflect current usage and understanding.

Similarly, the experimenters observed students having trouble responding to the longer, more complex sentences; these sentences were simplified and/or shortened. Still another issue arose pertaining to personal relevance of the sentences. We observed that if the self-referent statements were fairly general, they were more likely to be meaningful to a wider range of people. For example, a statement such as "My sister likes me" is too specific in that not all people have a sister. In contrast, a statement such as "Most people like me" is more useful in that it is likely to be relevant to most people. Accordingly, statements that were too specific were replaced by statements that were more general.

A final outcome of our investigation of mood induction resulted in construction of an instruction set that directed subjects to free-associate thoughts that were cued by the induction statements. To increase personal relevance of the mood induction statements, we designed an instruction set that directed subjects to express aloud thoughts evoked by each of the statements. This instruc- tion set encouraged subjects to actively engage in the procedure and, in addition, offered the opportunity for experimenters to observe the verbalized free associations that would otherwise be a private process.

\section{Validation of the Mood Induction Procedure}

Validation of the mood induction procedure was conducted in two separate studies. One study was an investigation of the effects of various mood states, induced by the present procedure, on the recall of perceptually grouped letter strings (Seibert \& Ellis, 1991). The second study examined the effects of mood states on immediate free recall of serially presented word lists (Ellis \& Seibert, 1991). In both studies, the DACL scores for happy and sad groups were reliably different from each other and from neutral scores. As noted earlier, the DACL is a commonly used measure to assess the effectiveness of a mood induction procedure. Higher scores indicate greater evidence of sadness or depression, whereas low scores are typical of subjects given a happy mood induction. The mean DACL scores obtained by Seibert and Ellis (1991) were: happy $=2.46$, sad $=16.77$, and neutral $=6.69$ [ANOVA, $F(2,36)=22.17, p<.001]$. The mean DACL scores obtained by Ellis and Seibert (1991) were: happy $=2.00$, sad $=18.47$, and neutral $=6.20$ [ANOVA, $F(2,87)=118.07, p<.001]$. These DACL scores are similar to those reported in studies using the Velten procedure (e.g., Leight \& Ellis, 1981).

In addition, recall performance by the happy and sad groups was reliably poorer than was that by the neutral group in both studies. Mean recall scores obtained by Seibert and Ellis were: happy $=1.62$, sad $=1.77$, and neutral $=4.62$ [ANOVA, $F(2,36)=28.75, p<.001$ ] Mean proportions of total recall obtained by Ellis and Seibert (1991) were: happy $=0.27$, sad $=0.23$, and neutral $=0.40$ [ANOVA, $F(2,87)=11.76, p<.05$ ]. In other words, both the happy and sad groups' performance suffered relative to the neutral condition in both studies, also paralleling the findings of Leight and Ellis (1981). In summary, the mood induction procedure produced sufficiently intense effects to be reliably reflected by both DACL and recall measures.

As noted above, the Velten (1968) mood induction procedure has been widely used in the cognition and emotion research and is in some ways similar to our mood induction procedure. Accordingly, we compared mean DACL scores obtained using the Velten (1968) procedure with mean DACL scores using our procedure and found no reliable differences. The Velten (1968) procedure was used by Ellis, Seibert, and Herbert (1990), who reported the following mean DACL scores: happy $=4.94$, sad = 14.94 , and neutral $=6.72$. Seibert and Ellis (1991) used the presently described mood induction procedure and obtained the following mean DACL scores: happy $=2.46$, sad $=16.77$, and neutral $=6.67$. Accordingly, it appears that our mood induction scales are at least as effective as Velten's.

Our scales included no reference to cognitive processing deficits or advantages as did Velten's (1968). For ex- 
ample, his depression scale included the statement "I just can't make up my mind, it's so hard to make simple decisions"; his elation scale included the statement "I'm able to do things accurately and efficiently." Both of these statements could suggest to the subject the kind of performance that was expected. Additionally, Velten's and our mood induction scales differed in that our scales did not include any reference to suicide or somatic states, whereas Velten's scale did (e.g., from Velten's depressed induction: "Sometimes I've wished I could die" and "I'm so tired").

\section{Mood Induction Scales}

After testing and revising the items, the final mood induction scales and instructions are shown in the Appendix. In using these scales, the sentences are paced at 20sec intervals, as is the case with Velten's (1968) procedure. In addition, 10 happy mood sentences are presented at the completion of each sad or neutral mood induction, prior to debriefing of subjects, in order to ensure that subjects leave the experiment in a reasonably happy mood.

\section{SUMMARY}

This paper describes an efficient, as well as effective, procedure for experimentally inducing various self-referenced mood states. Scales for inducing happy, sad, and neutral (control) transient mood states are provided. Each scale consists of 25 self-referent sentences designed to produce a happy, sad, or neutral mood. The effectiveness of each mood induction was demonstrated and can be conveniently assessed by typically used instruments that measure current mood states. More generally, the scales are shown to be useful in laboratory research investigating the effects of emotional mood states on memory and other cognitive processes. This set of mood induction procedures are composed of current language usage, self-referencing, effective in that they produce mood states that yield demonstrable performance effects on cognitive tasks, simple and concise, general enough to be meaningful across a wide range of college students, and appear to be transient in their effects on mood.

\section{REFERENCES}

Beck, A. T. (1978). Depression inventory. Philadelphia: Center for Cognitive Therapy.

Blaney, P. H. (1986). Affect and memory: A review. Psychological Bulletin, 99, 229-246.

Bower, G. H. (1981). Mood and memory. American Psychologist, 36, 129-148

BOWER, G. H., \& MAYER, J. D. (1989). In search of mood-dependent memory: Theory, research, and applications. In D. Kuiken (Ed.), Mood and memory: Theory, research, and applications [Special issue]. Jcurnal of Social Behavior \& Personality, 4, 121-156.

Brewer, D., Doughtie, E. B., \& LuBIN, B. (1980). Induction of mood and mood shift. Journal of Clinical Psychology, 36, 215-226.

Ellis, H. C., \& Ashbrook, P. W. (1988). Resource allocation model of the effects of depressed mood states on memory. In K. Fiedler \& J. Forgas (Eds.), Affect, cognition, and social behavior. Toronto: Hogrefe.

Ellis, H. C., \& Ashrrook, P. W. (1989). The "state" of mood and memory research: A selective review. In D. Kuiken (Ed.), Mood and memory: Theory, research, and applications [Special issue]. Journal of Social Behavior \& Personality, 4, 1-21.

Ellis, H. C., \& HUNT, R. R. (1989). Fundamentals of human memory and cognition (4th ed.), Dubuque, IA: W. C. Brown.

ELLIS, H. C., \& SEIBERT, P. S. (1991). Emotional mood states and immediate memory. Manuscript in preparation.
Ellis, H. C., Seibert, P. S., \& Herbert, B. J. (1990). Mood state effects on thought listing. Bulletin of the Psychonomic Society, 28, 147-150.

ForGas, J., \& Bower, G. H. (1988). Affect in social and personal judgments. In K. Fiedler \& J. Forgas (Eds.), Affect, cognition, and social behavior. Toronto: Hogrefe.

FrISWELl, R., \& MCCoNKEY, K. M. (1989). Hypnotically induced mood. Cognition \& Emotion, 3, 1-26.

GAGE, D. F., \& SAFER, M. A. (1985). Hemisphere differences in the mood state-dependent effect for recognition of emotional faces. Journal of Experimental Psychology: Learning, Memory, \& Cognition, 11, 752-763.

Hoh, S. H., McLennan, J., \& Ho, R. (1987). Depression related cognition: Attribution style and self-referent importance of negative events. Psychological Reports, 61, 718.

ISEN, A. M. (1984). Toward understanding the role of affect in cognition. In R. S. Wyer \& T. K. Srull (Eds.), Handbook of social cognition (Vol. 3, pp. 179-236). Hillsdale, NJ: Erlbaum.

Kenealy, P. M. (1986). The Velten mood induction procedure: A methodological review. Motivation \& Emotion, 10, 315-335.

KenEALY, P. M. (1988). Validation of a music mood induction procedure: Some preliminary findings. Cognition \& Emotion, 2, 41-48.

LeIGHT, K. A., \& Ellis, H. C. (1981). Emotional mood states, strategies, and state-dependency in memory. Journal of Verbal Learning \& Verbal Behavior, 20, 251-266.

LUBIN, B. (1965). Adjective checklists for measurement of depression. Archives of General Psychiatry, 12, 57-62.

MAYeR, J. D., \& Salovey, P. (1988). Personality moderates the interaction of mood and cognition. In K. Fiedler \& J. Forgas (Eds.), $A f$ fect, cognition, and social behavior. Toronto: Hogrefe.

McNair, D., Lorr, M., \& Droppleman, L. (1971). Profile of Mood States manual. San Diego, CA: Educational and Industrial Testing Service.

Pietromonaco, P. R., \& Markus, H. (1985). The nature of negative thoughts in depression. Journal of Personality \& Social Psychology, 48, 799-807.

Rholes, W. S., Riskind, J. H., \& LANe, J. (1987). Emotional mood states and memory biases: The effects of cognitive priming and mood. Journal of Personality \& Social Psychology, 52, 91-99.

SCheier, M. F., \& CARVER, C. S. (1977). Self-focused attention and the experience of emotion: Attraction, repulsion, elation, and depression. Journal of Personality \& Social Psychology, 35, 625-636.

SEIBERT, P. S., \& ElLIS, H. C. (1991). Irrelevant thoughts and memory during happy and sad mood states. Manuscript submitted for publication.

Sherwood, G. G., Schroeder, K. G., Abrami, L. E., \& Alden, L. E. (1981). Self-referent versus nonself-referent statements in the induction of mood states. Cognitive Therapy \& Research, 5, 105-108.

Sirota, A. D., \& SchwarTz, G. E. (1982). Facial muscle patterning and lateralization during elation and depression imagery. Journal of Abnormal Psychology, 91, 25-34.

Ucros, C. G. (1989). Mood state-dependent memory: A meta analysis. Cognition \& Emotion, 3, 139-167.

VELTEN, E. (1968). A laboratory task for induction of mood states. Behavioral Research \& Therapy, 6, 473-482.

Zuckerman, M., Lubin, B., Vogel, L., \& Valerius, E. (1964). Measurement of experimentally induced affects. Journal of Consulting Psychology, 28, 418-425.

\section{APPENDIX}

\section{Instructions For Mood Induction}

All Groups

1. I will read each of the following cards to myself and then I will read the card aloud.

\section{Sad and Happy Groups Only}

2. In this part of the experiment, I will be reading a series of cards with statements typed on them. These statements represent a mood state. In order to participate fully and successfully, I will need to be willing 
to feel and experience each statement as it would apply to me personally. In other words, when I read each statement, I will allow myself to respond as though the statement had been my own original thought. I will go with the feeling and not try to stop it.

3. At first I might feel like resisting the mood. However, I will see that it is the case that I have the opportunity to learn to talk myself into a mood, and obviously, I will also learn how to talk myself out of one. When this happens, I will find that I have learned something valuable about myself; I can learn to control my moods. Thus, I will try to experience the mood suggested.

4. I will feel each item, making the statement my own. I will experience the mood suggested and will not attempt to stop it. I will visualize a scene in which I have had such a feeling or thought. Then I will begin to say whatever comes to my mind that relates to the feeling. This is a type of free association-letting thoughts that pertain to the feeling flow freely.

5. I am now ready to experience the statements that follow. From this point forward whenever I hear the tone, I will go on to the next page. I will spend the time between the tones reading the statements and experiencing the feelings they suggest to me. I am ready to begin.

\section{Neutral Group Only}

2. From this point forward whenever I hear the tone, I will go on to the next page. I will spend the time between the tones reading the statements. I am ready to begin.

\section{Happy Mood Induction Scale}

1. Being in college makes my dreams more possible.

2. The world is full of opportunity and I'm taking advantage of it.

3. I know if I try I can make things turn out fine.

4. I bet things will go well for the rest of the day.

5. When I have the right attitude, nothing can depress me.

6. Most people like me.

7. I've got some good friends.

8. I can make things happen.

9. My parents brag about me to their friends.

10. I know I can get the things I want in life.

11. My future is so bright I've got to wear shades.

12. I feel creative.

13. Nothing can bum me out now.

14. Things look totally awesome.

15. The relationships I have now are the best I've ever had:

16. It doesn't get any better than this.

17. I can make any situation turn out right.

18. I feel completely aware.

19. I'm in charge of my life and I like it that way.

20. Life's a blast, I can't remember when I felt so good.

21. I'm going to have it all!

22. When it comes right down to it, I'm just too cool

23. I know I can do it; I'm going to seize the day!

24. I'm energized.

25. It's great to be alive!

Sad Mood Induction Scale

1. I feel a little down today.

2. My classes are harder than I expected.
3. Everyone else seems to be having more fun.

4. Sometimes I feel so guilty that I can't sleep.

5. I wish I could be myself, but nobody likes me when I am.

6. Today is one of those days when everything I do is wrong

7. I doubt that I'll ever make a contribution in the world.

8. I feel like my life's in a rut that I'm never going to get out of.

9. My mistakes haunt me, I've made too many.

10. Life is such a heavy burden.

11. I'm tired of trying.

12. Even when I give my best effort, it just doesn't seem to be good enough.

13. Nobody understands me or even tries to.

14. I don't think things are ever going to get better.

15. I feel worthless.

16. What's the point of trying?

17. My parents don't know who I am

18. When I talk no one really listens.

19. I feel cheated by life.

20. Why should I try when I can't make a difference anyway?

21 . Sometimes I feel really guilty about the way I've treated my parents.

22. Every time I turn around, something else has gone wrong.

23. I'm completely alone.

24. There is no hope.

25. I feel I am being suffocated by the weight of my past mistakes.

\section{Neutral (Control) Mood Induction Scale}

1. There are sixty minutes in one hour.

2. A neuron fires rapidly.

3. New Mexico is in the United States.

4. Apples are harvested in the Fall.

5. Basket weaving was invented before pottery making.

6. Some baseball bats are made from the wood of the ash tree.

7. The Shakers invented the circular saw.

8. It snows in Idaho.

9. Perennials bloom every year.

10. Arizona has both deserts and pine covered mountains.

11. You have to take the ferry to get to the island.

12. Santa Fe is the capital of New Mexico.

13. Elephants carried the supplies.

14. The Pacific Ocean has fish.

15. Most high schools have a band.

16. The rug was made according to an old Navajo pattern.

17. Some think that electricity is the safest form of power.

18. Most oil paintings are done on canvas.

19. Many buildings in Washington were made of marble.

20. Corn is sometimes called maize.

21. An orange is a citrus fruit.

22. Some say that lady bugs are good for the garden.

23. New York City is in New York State.

24. Diamonds really can cut glass.

25 . Some chimps have been taught to use sign language. 